\title{
Effects of Newly-Developed Superimposed Binaural Beat on Anxiety in University Students in Thailand: A Randomised Controlled Trial
}

\author{
Wuthichai Chairinkam ${ }^{1}$, Lakkana Thaikruea ${ }^{1^{*} \text {, }}$ \\ Jakkrit Klaphajone ${ }^{2}$, and Peerasak Lerttrakarnnon ${ }^{3}$ \\ ${ }^{I}$ Department of Community Medicine, Faculty of Medicine, Chiang Mai University, Chiang Mai \\ 50200, Thailand \\ ${ }^{2}$ Department of Rehabilitation Medicine, Faculty of Medicine, Chiang Mai University, Chiang Mai \\ 50200, Thailand \\ ${ }^{3}$ Department of Family Medicine, Faculty of Medicine, Chiang Mai University, Chiang Mai \\ 50200, Thailand \\ *Corresponding author.E-mail: lakkana.t@cmu.ac.th \\ https://doi.org/10.12982/CMUJNS.2019.0010
}

Received: July 14, 2018

Revised: October 12, 2018

Accepted: October 21, 2018

\begin{abstract}
This study aimed to investigate the effects of superimposed binaural beat in reducing anxiety among university students and to compare the effects of superimposed binaural beat to those of receptive music listening and relaxation treatment. The 134 participants who participated in the double-blind randomised controlled trial were randomly selected from 539 students with anxiety. According to block randomisation, the participants were assigned to superimposed binaural beat $(n=45)$, receptive music listening $(n=45)$, and blank audio (Control, $n=44$ ) groups. All three groups received general relaxation treatment in 20-minute daily sessions over a period of 5 consecutive days. The median differences in anxiety level were measured by the self-administered State-Trait Anxiety Inventory form-Y before and after treatment for the superimposed binaural beat, music listening, and control groups at $-20.00,-16.00$, and -15.00 , respectively. The differences between the superimposed binaural beat group and the control $(P=0.04)$ and music listening $(P=$ $0.02)$ groups were statistically significant. Anxiety levels were effectively reduced in $100 \%$ of participants in the superimposed binaural beat group, which was higher than the rate in the control group (84.09\%: $P<0.01)$. Superimposed binaural beat-based interventions may reduce anxiety in university students more effectively than the music listening and general relaxation methods. The research findings are potentially beneficial for policymakers and for developing interventions aimed at reducing anxiety in university students.
\end{abstract}

Keywords: Anxiety, Student, Music listening, Superimposed binaural beat, Relaxation, Randomised controlled trial, Effect 


\section{INTRODUCTION}

Anxiety problems in university students have been increasing due to academic pressure such as graduation expectation, academic achievement and financial problems (Saipanich, 2003; Vaez et al., 2006; Shamsuddin et al., 2013; Yusoff et al., 2013). Study in the United States found $12.00 \%$ of students to have experienced anxiety issues in the previous year. Over $50 \%$ of university students reported feeling hopeless and overwhelming anxiety over the past 12 months (Regehr et al., 2013). In Egypt, medical students have indicated that anxiety has great impact on well-being in terms of studying for and participating in examinations (Yusoff et al., 2013). These negative effects bring concern physical and mental problems as the data claimed by the health care centre of each university, where increasing numbers of students are requesting services (Alzahem et al., 2011; Galbraith and Brown, 2011). Moreover, 11.40\% of university students were found to require psychological help from university counselling centres, and this number is likely to increase (Grasgreen, 2012). Approximately $40.00 \%$ of university students have stated that their mental health problems required psychological help beginning with anxiety, which is one of the main causes of mental health problems. Anxiety is recognised by medical professionals as a causal factor of mental health problems (Grasgreen, 2011). In Thailand, anxiety has a negative impact on the academic performance and emotions of medical students (Saipanich, 2003).

Common anxiety treatments include medication, which is associated with both physical and economic short- and long-term burdens (Department of Mental Health, 2013). Anxietyrelief medication is commonly used to help reduce anxiety. Other treatments such as muscle relaxation, listening to music, and psychotherapy, which requires specialist guidance, are available, but might be inconvenient to access. One study indicated that music was able to reduce anxiety (Shamsuddin et al., 2013) and there has been an evolution in the application of music with a binaural beat.

Binaural beat arises from the interaction of bilateral input at higher levels of the ascending auditory pathway (Tobias, 1963; Rutschmann and Rubinstein, 1965). The mechanism of action is two-way with effects on the limbic system, which regulates mood, and on brainwave entrainment. Binaural beat is reportedly generated within the brain. The superior olivary complex is believed to be the first nucleus to receive auditory information from both sides of the ears and binaurally activated phase-sensitive neurons are also found in the inferior colliculus (Spitzer and Semple, 1998; Schwarz and Taylor, 2005). The fluctuation in frequency equals the difference in the two pure tones presented. However, a classic study reported that the maximum difference in two tones that humans can perceive as a beat is $35 \mathrm{~Hz}$; otherwise, two separate pure tones are perceived instead (Oster, 1973).

Listening to $7-10 \mathrm{~Hz}$ binaural beats may be beneficial in reducing mild anxiety (Le Scouarnec et al., 2001; Wahbeh et al., 2007) and improving self-reported relaxation (McConnell et al., 2014). For clinical interventions, binaural beat has the potential of decreasing acute preoperative anxiety in patients undergoing general surgery (Padmanabhan et al., 2005) and reducing anxiety in moderately-anxious patients in the emergency department by $10-15 \%$ (Weiland et al., 2011). Binaural beat embedded in music listening may have benefits in music interventions alone by decreasing anxiety in patients undergoing operative cataract surgery (Wiwatwongwana et al., 2016) and may be useful in reducing preoperative anxiety in dental 
surgery (Isik et al., 2017). However, another study found that binaural beat showed positive effects on anxiety among anxious populations, but the difference was statistically insignificant (Le Scouarnec et al., 2001).

Superimposed binaural beat is a new binaural beat technique in which additional binaural beats are synthesised on the basis of frequency shifting of the sound waves from each traditional Thai musical instrument, except for drum sounds (due to their extremely low frequency), in addition to the original binaural beats created by the standard method of puretone sine wave-frequency differentiation. It is expected that superimposed binaural beat's quality and efficiency will be better than that of traditional binaural beat. Currently, traditional binaural beats are used to reduce anxiety in patients in clinical trials, but none of these trials have employed superimposed binaural beats.

This study aimed to investigate the effects of superimposed binaural beats on reducing anxiety among university students and to compare the effects of superimposed binaural beat to the effects of music listening and relaxation treatment.

\section{METHODS}

\section{Participants for anxiety assessment}

The data collection of this research was conducted with a sample of 1,245 from among 6,480 university students based on stratification of faculty and academic year over a 4-week period from October to November 2016. The prevalence of acute anxiety was determined among 1,245 health-science students using the State-Trait Anxiety Inventory (STAI) form Y-I (state anxiety) with a cut-off score of 40 or higher (Kennedy et al., 2001). After drawing lots, a random sequence of numbers was computer generated and used in each stratum of simple random sampling. Overall, 539 of 1,245 students had anxiety scores of 40 or higher (eligible for the randomised control trial (RCT)).

\section{Participants for the RCT}

No student had a history of epilepsy, severe heart disease, or depressive symptoms (which were the exclusion criteria applied before sampling for the RCT) and 134 of 539 students were randomly selected (a random sequence of numbers was computer generated) to participate in the double-blind RCT (neither the researcher nor the participants knew what treatment was received). According to block randomisation, the participants were assigned to one of three of the following treatment groups: superimposed binaural beat (45 students), music listening (45 students), and blank audio (44 students). All three groups received general relaxation treatment, which involved resting while sitting in a comfortable chair in a room at a pleasant temperature and wearing stereo headphones; this treatment is basic therapy received by everyone and prevents confounders.

The superimposed binaural beat, music listening, and control groups listened to Thai Lanna music with superimposed binaural beat tones (with $10 \mathrm{~Hz}$ difference), Thai Lanna music without superimposed binaural beat, and blank audio, respectively. They received 20-minute daily treatments for 5 consecutive days. The participants were excluded if any complications 
arose, including anxiety events or other treatments. Anxiety levels were measured by the selfadministered STAI Form-Y (STAI-S) before and after treatment. The STAI-S is a 20-item selfreported measure of state or current anxiety; all items were rated on a 4-point scale. Internal consistency coefficients for the scale range from 0.86 to 0.95 ; test-retest reliability coefficients range from 0.65 to 0.75 over a 2-month interval (Spielberger et al., 1983; Julian, 2011). The researchers prevented the interference of time-dependent confounders (alcohol use, receipt of other treatments, and use of anti-anxiety medication) and major confounders (physical illness or tragic events causing anxiety) by notifying all participants at the recruitment stage and monitoring using a daily questionnaire.

\section{Superimposed binaural beat Creation}

The superimposed binaural beat innovation in the present study used Thai Lanna music, which is familiar to students in northern Thailand. Additional binaural beats were synthesised on the basis of frequency shifting of the sound waves from each traditional Thai musical instrument, except the drum sounds (due to their extremely low frequency), apart from the original binaural beat, which was created by the standard method of pure-tone sine wave frequency differentiation via a self-hypnosis and relaxation machine (SHARM, Cyber Team Ltd., USA) (Version 2.4). The continuous sounds, namely, strings and organs, were also arranged to be inserted into all songs in order to render continuous the frequency difference between the ears with the least interruption between the songs. All eligible tracks of each musical instrument were set to produce $10-\mathrm{Hz}$ differences between one ear with a lower carrier frequency and the other with a higher carrier frequency. The therapeutic frequency of $10 \mathrm{~Hz}$ was sustained for at least 20 minutes to ensure sufficient time to entrain the brainwaves at the alpha level (Chiang Mai University copyright on the synthesis of superimposed binaural beats).

\section{Statistical analysis}

Descriptive analysis included frequency, percentage and mean. Univariate analysis included Fisher's exact test and the chi-squared and and Kruskal-Wallis tests, depending on the data distribution. A $P$-value of below 0.05 was considered statistically significant. Data management and analyses were performed by using Epi Info for Windows (Version 3.5.4; Centers for Disease Control and Prevention, Atlanta, GA) and STATA version 11 (Statacorp LP. College Station, TX).

\section{Ethical consideration}

All methods were carried out in accordance with relevant guidelines and regulations. All experimental protocols were approved by the Ethics Committee of the Faculty of Medicine, Chiang Mai University, and cooperation was received in collecting information from the School of Health Science, University of Phayao, (Study Code: COM-2559-03951/ Research ID: 3951 Ethics Approval Number 319/2016). Informed consent was obtained from all participants. 


\section{RESULTS}

\section{Baseline characteristics}

One hundred and thirty-four students with anxiety were enrolled in the study. The participants were subsequently assigned to the superimposed binaural beat, music listening, and control groups with 45, 45, and 44 students with anxiety in each group, respectively. Most participants were first-year female students (Table 1). The participants were comparable in terms of demographic characteristics (Table 1). The median trait anxiety scores of the superimposed binaural beat, music listening, and control groups were 43.00 (range: 34.00 to 69.00 ), 43.00 (range: 35.00 to 62.00 ), and 43.50 (range: 32.00 to 64.00 ), respectively.

Table 1. Baseline characteristics of the participants by treatment group.

\begin{tabular}{|c|c|c|c|}
\hline \multirow[b]{2}{*}{ Variables } & \multicolumn{3}{|c|}{ Group* } \\
\hline & $\begin{array}{c}\text { SBB } \\
n=45\end{array}$ & $\begin{array}{c}\text { ML } \\
n=45\end{array}$ & $\begin{array}{c}\text { Control } \\
n=44\end{array}$ \\
\hline \multicolumn{4}{|l|}{ Sex n $(\%)$} \\
\hline Male & $6(13.33)$ & $6(13.33)$ & $8(18.18)$ \\
\hline Female & $39(86.67)$ & $39(86.67)$ & $36(81.82)$ \\
\hline \multicolumn{4}{|l|}{ Year } \\
\hline 1 & $17(37.78)$ & $21(46.67)$ & $18(40.91)$ \\
\hline 2 & $15(33.33)$ & $11(24.44)$ & $10(22.73)$ \\
\hline 3 & $12(26.67)$ & $12(26.67)$ & $16(36.36)$ \\
\hline 4 & $1(2.22)$ & $1(2.22)$ & $0(0.00)$ \\
\hline \multicolumn{4}{|l|}{ Faculty n (\%) } \\
\hline Medical & $27(60.00)$ & $26(57.77)$ & $26(59.09)$ \\
\hline Pharmaceutical & $2(4.44)$ & $3(6.67)$ & $4(9.09)$ \\
\hline Nursing & $4(8.89)$ & $4(8.89)$ & $3(6.82)$ \\
\hline Medical Science & $2(4.44)$ & $3(6.67)$ & $3(6.82)$ \\
\hline Allied Health Science & $10(22.23)$ & $9(20.00)$ & $8(18.18)$ \\
\hline
\end{tabular}

Note: $\mathrm{SBB}=$ Superimposed Binaural Beat; $\mathrm{ML}=$ Busic Listening; Control = Blank audio.

\section{Effects of treatment on anxiety levels}

During the treatment period, there were no reports of alcohol use, receipt of other treatments or anti-anxiety medication, physical illness, or tragic events. The median difference in the STAI-S score between after and before treatments of the superimposed binaural beat, music listening, and control groups was $-20.00,-16.00$, and -15.00 , respectively. When comparing the median differences among the groups, the superimposed binaural beat group versus the control group and the superimposed binaural beat group versus the music listening group had statistically significantly different scores (Table 2). 
Table 2. Anxiety levels among participants by treatment group.

\begin{tabular}{lcc}
\hline Groups & $\begin{array}{c}\text { Different STAI-S scores* } \\
\text { median (range) }\end{array}$ & $\boldsymbol{P}$-value \\
\hline SBB & $-20.00(-3.00$ to -40.00$)$ & SBB versus ML: $0.02^{* *}$ \\
ML & $-16.00(1.00$ to -32.00$)$ & ML versus Control: 0.81 \\
Control & $-15.00(0$ to- 50.00$)$ & Control versus SBB: $0.04 * *$ \\
\hline
\end{tabular}

Note: $\mathrm{SBB}=$ Superimposed Binaural Beat; $\mathrm{ML}=$ Music Listening; Control = Blank audio; * Different median STAI-S pre- and post-test scores; ** Statistically significant difference using Kruskal-Walis test.

\section{Anxiety level rates reached by treatments}

The students were considered to have acute anxiety when their anxiety scores were 40 points or higher. Thus, the participants who had anxiety scores lower than 40 points after treatment were considered as normal. All participants $(100.00 \%)$ in the superimposed binaural beat group, 43 participants $(95.56 \%)$ in the music listening group, and 37 participants $(84.09 \%)$ in the control group experienced reduced anxiety at the end of the 5-day treatment period, (see Table 3).

Table 3. Comparison of anxiety normal rates after completed treatment in the SBB, ML, and control Groups.

\begin{tabular}{lccc}
\hline Groups & n & $\begin{array}{c}\text { Normal } \\
\text { n (\%) }\end{array}$ & $\boldsymbol{P}$-value* \\
\hline SBB & 45 & $45(100.00)$ & 0.045 \\
ML & 45 & $43(95.56)$ & \\
Control & 44 & $37(84.09)$ & \\
\hline
\end{tabular}

Note: SBB $=$ Superimposed Binaural Beat; ML = Music Listening; Control = Blank audio; $*$ Statistical significance by Kruskal-Wallis test.

\section{DISCUSSION}

Binaural beat has been used to reduce anxiety levels in numerous studies (Padmanabhan et al., 2005; Weiland et al., 2011; Wiwatwongwana et al., 2016; Isik et al., 2017), yielding both effective and ineffective results (Le Scouarnec et al., 2001). No previous study has used binaural beat with music by shifting the frequency of the sound of each instrument, using a 10$\mathrm{Hz}$ difference between the left and right spectrums with pure binaural beat tones on one track. In the present study, combining the additional superimposed binaural beat innovation with the original binaural beat was expected to enhance the power of brainwave entrainment in participants who listened to this music continuously. The results revealed that all participants in the superimposed binaural beat group experienced reduced anxiety, whereas fewer participants improved in the other two groups. The STAI-S scores decreased dramatically in the superimposed binaural beat group (median -20.00), and the difference was statistically 
significant compared to the control group scores. At the same time, the difference in STAI-S scores between the music listening and the control groups was not statistically significant. The reasons proposed for the effects of music listening include music composition passing into the nervous system, neurotransmitters and limbic system resulting in both physical and emotional changes (Weiland et al., 2011) including parasympathetic nervous-system activation such as slowing the heart rate, dilating blood vessels, and lowering blood pressure (Wahbeh, et al., 2007). The alpha wavelength reflects the relaxation state.

Original binaural beat produced by the machine mentioned in previous study, was also used in this study to investigate the anxiolytic effects of binaural beat among patients undergoing cataract operations. The patients in the music listening and binaural beat groups showed significantly lower STAI-S scores compared with the control group. However, the difference between the music listening and superimposed binaural beat groups was statistically insignificant. The mean STAI-S score of the music listening group was -7.00 and that of the superimposed binaural beat group was -9.00 (Wiwatwongwana et al., 2016). Although the findings of the present study indicated that the superimposed binaural beat group showed higher different scores was believed to enhance the power of brainwave entrainment. There are some studies used superimposed binaural beat to reduce anxiety in some patients (Padmanabhan et al., 2005; Wiwatwongwana et al., 2016). However there is no study in university student before, the result of this study will be useful for decreasing anxiety in students population.

The limitation of this study might be that the study explored anxiety among a subgroup of students studying in the field of health science with high anxiety. Therefore, it may not be appropriate to generalise the findings to other populations. The advantages of this study were the research design, large sample size, and double-blind methodology. The study was an RCT with time-dependent confounder control to provide immediate interventions in the least amount of time for effectively reducing anxiety levels. Thus, we contest that these dependent confounders had no effect on the anxiety levels. The participants were selected by simple random sampling to ensure highly homogenous characteristics. The RCT was double-blind to prevent selection and information biases. The major confounding variables were monitored daily during the study period. It is believed that the results of the experiments were due to the power of the superimposed binaural beat.

The findings of this study are potentially useful for policymakers and for developing interventions aimed at reducing anxiety in university students by tailoring the methodology to an adolescent context. Superimposed binaural beat-based interventions may reduce anxietyrelief medication use, as well as the cost and side effects of medical treatment. This type of intervention can also be conducted in large numbers of target groups in settings with few student-affair officers, as is the case in nearly all universities in developing countries. It is worth exploring the possibility of using superimposed binaural beat paradigms in other population groups.

In conclusion, the findings of this double-blind RCT illustrate that superimposed binaural beat-based interventions may reduce anxiety in university students more effectively than the music listening and general-relaxation methods. These findings will potentially contribute to inexpensive and safe treatment options to address high demands in university settings. 


\section{ACKNOWLEDGEMENT}

The researchers would like to express sincere gratitude to the School of Health Science, University of Phayao for supporting the study. We would also like to thank the students for participating in the study.

\section{REFERENCES}

Alzahem, A.M., Van der Molen, H.T., Alaujan, A.H., Schmidt, H.G., and Zamakhshary, M.H. 2011. Stress among dental students: a systematic review. European Journal of Dental Education. 15(1): 8-18. https://doi.org/10.1111/j.1600-0579.2010.00640.x

Department of Mental Health. 2013. Annual report of department of mental health fiscal year 2009-2011.

Galbraith, N.D., and Brown, K.E. 2011. Assessing intervention effectiveness for reducing stress in student nurses: A qualitative systematic review. Journal of Advanced Nursing. 67(4): 709-721. https://doi.org/10.1111/j.1365-2648.2010.05549.x

Grasgreen A. 2011. College counseling directors' survey finds salary disparity students with anxiety other psychological problems [Internet]. [cited $2016 \mathrm{Jul}$ 5]. Available from https://www.insidehighered.com/news/2016/07/05/survey-counseling-centerdirectors-finds-anxiety-and-depression-are-top-issues

Grasgreen A. 2012. Students rate mental health services [Internet]. [cited 2012 Oct 30]. Available from http://www.insidehighered.com/news/2012/10/30/colleges-dontalwayshelp-mental-health-issues-student-surveyshows

Isik, B.K., Esen, A., Buyukerkmen, B., Kilinc, A., and Menziletoglu, D. 2017. Effectiveness of binaural beats in reducing preoperative dental anxiety. The British Journal of Oral and Maxillofacial Surgery. 55(6): 571-574. https://doi.org/10.1016/j.bjoms.2017.02.014

Julian, L.J. 2011. Measures of anxiety: State-Trait Anxiety Inventory (STAI), Beck Anxiety Inventory (BAI), and Hospital Anxiety and Depression Scale-Anxiety (HADS-A). Arthritis Care \& Research (Hoboken). 63 (Suppl. 11): S467-72 https://doi.org/10.1002/ acr.20561

Kennedy, B.L., Schwab, J.J., Morris, R.L., and Beldia, G. 2001. Assessment of state and trait anxiety in subjects with anxiety and depressive disorders. Psychiatric Quarterly. 72: 263. https://doi.org/10.1023/A:1010305200087

Le Scouarnec, R.P., Poirier, R.M., Owens, J.E., Gauthier, J., Taylor, A.G., and Foresman, P.A. 2001. Use of binaural beat tapes for treatment of anxiety: a pilot study of tape preference and outcomes. Alternative Therapies in Health and Medicine. 7(1): 58-63.

McConnell, P.A., Froeliger, B., Garland, E.L., Ives, J.C., and Sforzo, G.A. 2014. Auditory driving of the autonomic nervous system: Listening to theta-frequency binaural beats post-exercise increases parasympathetic activation and sympathetic withdrawal. Frontiers in Psychology. 5: 1248. https://doi.org/10.3389/fpsyg.2014.01248

Oster G. 1973. Auditory beats in the brain. Scientific American. 229(4): 94-102.

Padmanabhan, R., Hildreth, A.J., and Lawa, D. 2005. A prospective, randomized, controlled study examining binaural beat audio and pre-operative anxiety in patients undergoing general anesthesia for day case surgery. Anaesthesia. 60(9): 874-877. https://doi. $\operatorname{org} / 10.1111 / \mathrm{j} .1365-2044.2005 .04287 . \mathrm{x}$ 
Regehr, C., Glancy, D., and Pitts, A. 2013. Interventions to reduce stress in university students: A review and meta-analysis. Journal of Affective Disorders. 148(1):1-11. https://doi. org/10.1016/j.jad.2012.11.026

Rutschmann, J., and Rubinstein, L. 1965. Binaural beats and binaural amplitude-modulated tones: successive comparison of loudness fluctuations. Journal of the Acoustical Society of America. 38(5). https://doi.org/10.1121/1.1909802

Saipanich, R. 2003. Stress among medical students in a Thai medical school. Medical Teacher. 25(5): 502-506. https://doi.org/10.1080/0142159031000136716

Schwarz, D.W., and Taylor, P. 2005. Human auditory steady state responses to binaural and monaural beats. Journal of the international Federation of Clinical Neurophysiology. 116(3): 658-668. https://doi.org/10.1016/j.clinph.2004.09.014

Shamsuddin K., Fadzil, F., Ismail, S.W.W, Shah, S.A., Omar, K., Muhammad, N.A., Jaffar, A., Ismail, A., and Mahadevan, R. 2013. Correlate of depression, anxiety and stress among Malaysian University students. Asian Journal of Psychiatry. 6(4): 318-323. https://doi. org/10.1016/j.ajp.2013.01.014

Spielberger, C.D., Gorsuch, R.L., Lushene, R., Vagg, P.R., and Jacobs, G.A. 1983. Manual for the State-Trait Anxiety Inventory. Palo Alto, CA: Consulting Psychologists Press.

Spitzer, M.W., and Semple, M.N. 1998. Transformation of binaural response properties in the ascending auditory pathway: influence of time-varying interaural phase disparity. Journal of Neurophysiol. 80(6): 3062-76. https://doi.org/10.1152/jn.1998.80.6.3062

Tobias, J.V. 1963. Application of a "Relative" procedure to a problem in binaural beat perception: Report Civil Aeromedical Research Institute US. 26: 1-8.

Vaez, M., Ponce de Leon, A., and Laflamme, L. 2006. Health related determinants of perceived quality of life: a comparison between first year university student and third working peers. Work. 26: 167-177.

Wahbeh, H., Calabrese, C., Zwickey, H., and Zaidel, D. 2007. Binaural beat technology in humans: a pilot study to assess neuropsychologic, physiologic, and electroencephalographic effects. Journal of Alternative Complement Medical. 13(2): 199-206. https://doi.org/10.1089/act.2007.13401

Weiland, T.J., Jelinek, G.A., Macarow, K.E., Samartzis, P., Brown, D.M., Grierson, E.M., and Winter C. 2011. Original sound compositions reduce anxiety in emergency department patients: a randomized controlled trial. The Medical Journal of Australia. 19(11-12):195.

Wiwatwongwana, D., Vichitvejpaisal, P., Thaikruea, L., Klaphajone, J., Tantong, A., and Wiwatwongwana, A. 2016. The effects of music with and without binaural beat audio on operative anxiety in patients undergoing cataract surgery: a randomized controlled trial. Eye. 30(11): 1407-1414. https://doi.org/10.1038/eye.2016.160

Yusoff, M.S., Abdul Rahim, A.F., Baba, A.A., Ismail, S.B,, Mat Pa, M.N., and Esa, A.R. 2013. Prevalence and associated factors of stress, anxiety and depression among prospective medical students. Asian Journal of Psychiatry. 6(2): 128-133. https://doi.org/10.1016/j. ajp.2012.09.012 